\title{
Complementary Feeding Self-efficacy: A Concept Analysis
}

\author{
Heni Hendriyani ${ }^{1,2 *}$, Toto Sudargo ${ }^{3}$, Lely Lusmilasari ${ }^{4}$, Siti Helmyati ${ }^{3}$, Susetyowati Susetyowati ${ }^{3}$, Ricvan Dana Nindrea ${ }^{1}$ \\ ${ }^{1}$ Doctoral Program, Faculty of Medicine, Public Health and Nursing, Universitas Gadjah Mada, Yogyakarta, Indonesia; \\ ${ }^{2}$ Department of Nutrition, Health Polytechnic of Semarang Ministry of Health Indonesia; ${ }^{3}$ Nutrition and Health Program, Faculty \\ of Medicine, Public Health and Nursing, Universitas Gadjah Mada, Yogyakarta, Indonesia; ${ }^{4}$ Nursing Science Program, Faculty \\ of Medicine, Public Health and Nursing, Universitas Gadjah Mada, Yogyakarta, Indonesia
}

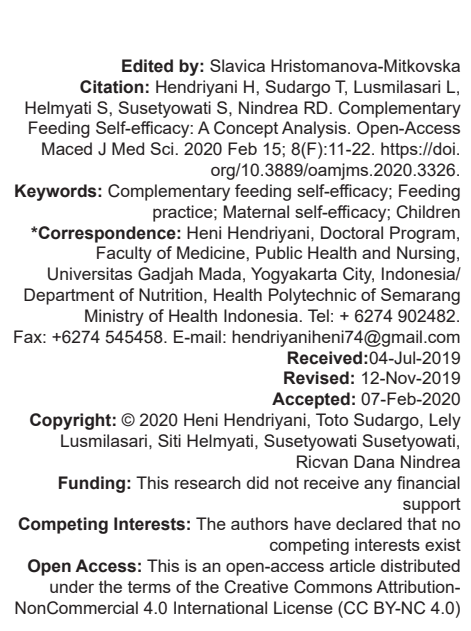

\section{Introduction}

In developing knowledge, one essential aspect is concept development. The concept itself is defined as "something conceived in the mind, thought, notion, and an abstract or generic idea generalized from particular instances [1]. Walker and Avant stated that concept analysis is a process that recognizes unique attributes of a concept, offers a precise operational definition of the concept, and expands communication regarding the concept [2].

Complementary feeding is a crucial aspect of children's health and growth. Its significant role in child health and development has been widely recognized [3], [4]. The first 2 years of life is the time when malnutrition starts in many young children, causing a high prevalence of malnutrition in children under 5 years of age globally. It is estimated that two out of five children are stunted in low-income countries [5]. Few children receive adequate nutrition with safe complementary foods; research shows less than a fourth of infants under 2 years of age in many undeveloped and developed countries meet the criteria of dietary diversity and feeding frequency that is age appropriate [5].

Factors that are considered essential in the effort to implement adequate complementary feeding include the variety of foods in the household and feeding practices of caregivers [5]. One study showed that few mothers provided an adequate quantity of complementary foods [6]. Mothers or caregivers have an important role in preparing and giving complementary feeding to young children. Culture and tradition, maternal family members' food preparation behaviors, including food preparation self-efficacy and attitudes toward healthy eating, were the prominent factors impelling food preparation behaviors [7]. Foods that have been prepared by mothers or caregivers and given to the child constitute part of the daily feeding practices. Feeding practices also refer to the specific goal-directed behaviors used by parents that effect the children's eating habits [8]. Common feeding practices include modeling eating behaviors, restricting certain types of food, pressuring children to eat, rewarding positive behaviors with food, and availability of food at home [8]. 
Meanwhile, some study results revealed that to deliverappropriatefeeding practice totheiryoung children, certain skills were essential for caregivers [5]. One study found that developing caregiving skills, including infant and young child feeding practices can be effective in reducing the negative effects of food shortage and low maternal education [9]. By having cooking skills, mothers/caregivers can determine which ingredients and food are appropriate for family meals. With selfefficacy, mothers/caregivers will have more power to provide nutritious food for both their family and young children. It is related to mothers/caregivers self-reliance in being able to deliver nutritious meals when either food or financial resources are limited [10].

The concept of complementary feeding selfefficacy has not been well-defined so far. Therefore, it is very useful to develop the concept since complementary feeding practice is a complex activity that needs specific knowledge and skills to perform. Accordingly, the concept of complementary feeding self-efficacy was selected for analysis because of its importance in child nutrition and health. This study addresses the gaps in and limited availability of formal analysis in the nutrition literature to define complementary feeding self-efficacy in a manner that best fits the profession of the nutrition discipline.

The term feeding self-efficacy is very general and does not focus on the complementary feeding behavior, which is a very specific activity. Studies regarding how self-efficacy is related to behavior change for complementary feeding practices are still limited [11]. Complementary feeding can be challenging and is often characterized by poor feeding practices and poor dietary quality [12]. Complementary foods for children need to be more nutritious compared to family foods. Yet, the opposite usually happens in most low-income households. The foods are often of low nutritive value with low protein, low energy density, and high bulk [13].

It is considered important to analyze the complementary feeding self-efficacy concept since it is a crucial aspect among mothers when giving food to their children. Self-efficacy, as a behavior-specific concept, can differ across distinct groups of behaviors [14]. The study aimed to analyze the concept of complementary feeding self-efficacy, specifically focusing on the caregivers and their daily feeding practices through a literature review examining the use of current concepts and critical attributes.

\section{Materials and Methods}

\section{Material and research sample}

This research conducted using concept analysis. Concept analysis of the findings from the literature review used the method developed by Walker and Avant. It consists of (1) select a concept; (2) determine the aims or purposes of analysis; (3) identify all uses of the concept; (4) determine the defining attributes; (5) identify a model case; (6) identify a borderline, related, contrary, invented, and illegitimate cases; (7) identify antecedents and consequences; and (8) define empirical referents. The research samples included published research articles from January 1998 to December 2018 in article databases of PubMed and ProQuest.

\section{Research procedure}

This study was done by collecting data from published research articles on complementary feeding self-efficacy in article databases of PubMed and ProQuest (Figure 1).

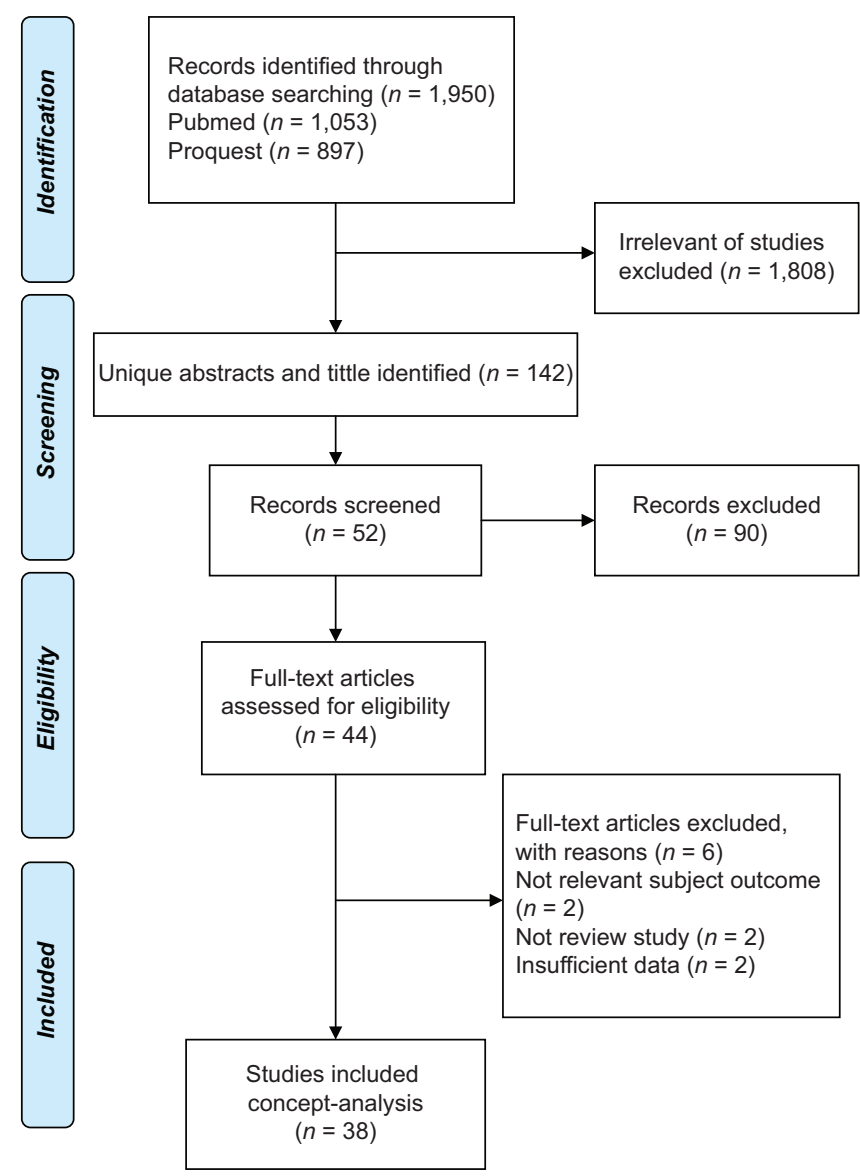

Figure 1: Flow diagram of sources included

The identification process of the 1950 articles was conducted by reviewing the article titles, then continued by reviewing the abstract and their full-text. The articles were excluded if (1) irrelevant to subjects of study, (2) the study methods were neither review study, or (c) the data provided in the study results section were not appropriate for extraction.

\section{Data collection technique}

The data collection was done by online searching with keywords: Feeding practices AND 
self-efficacy AND mothers AND maternal AND confident AND infant. The search was limited to papers in English. The date of publication was limited from January 1998 to December 2018. The article type was limited to review articles. The research subject was limited to human subject research. The abstracts of articles with relevant titles were assessed, while the irrelevant ones were excluded from the study. Furthermore, the articles included were reviewed in full-text form, and afterward any irrelevant full-text articles were excluded from the study. The inclusion criteria of this study sample were relevant research on feeding self-efficacy with review study methods. The exclusion criteria were either the article was not available in full-text form or the criteria were not met for inclusion, or if the information provided was not proper for data extraction. Two independent investigators carefully extracted information from all articles included in accordance with the standardized protocol. Disagreements were resolved by input from three other investigators.

\section{Results}

\section{Identify current uses of the concept}

In conducting the literature search using the selected databases, specific words were included, such as feeding practices, self-efficacy, mothers, maternal, confidence, and infants. The concept of self-efficacy, particularly in health and nutrition-related behaviors, has been used in different settings and aspects. The terms include maternal self-efficacy, maternal feeding competencies, and maternal confidence.

One of the concepts that have been used widely related to care in nutrition is maternal self-efficacy. Maternal self-efficacy refers to "mother's self-referent estimation of competence in her parental role, or as a mother's perception of her ability to positively influence the behavior and development of her children" [15]. A study conducted by Kolopaking et al. in urban areas of Jakarta revealed that maternal self-efficacy involves a mother's confidence in providing foods that meet their children's appetites and cooking the meals by themselves. Most preferred to provide easy to cook meals and purchased ready to eat food [16]. Some studies used the self-efficacy concept and related it with various food behaviors such as the relation of selfefficacy and weight change [17], eating patterns and overweight control [18], lack of eating control [19], fat consumption [20], and fruits and vegetables intake [21]. The results of most of these studies showed that self-efficacy is an important factor in the prediction of nutrition behaviors.

It has also been reported that increased self-efficacy is associated with the improvement of nutritional health behaviors. One study conducted by
Salarkia et al. showed that the relationship between food insecurity and maternal infant feeding styles was mediated by mother's self-efficacy. The study suggested that empowering and improving mothers' self-efficacy so that they can handle poor and restricted food resources can revise their feeding behaviors [22].

The study by Pridham et al. suggested that infant's positive experience, effectiveness, and satisfaction in feeding and regulated feeding interaction are supported by affective and behavioral qualities of mother-infant interaction and that all will have effect on the infant's optimal nutrient intake. Thus, maternal feeding competency is developed by the existence of a positive attendance in affect and behavior, sensitive responsiveness and immersion with the infant, regulation and inhibition of negative affect, and emotional and cognitive support of the infant's feeding and feeding interaction. Support for infant's constructive feeding experience is conveyed affectively and behaviorally in visual and verbal interaction, positive affect, enjoyment, social initiative, connectedness, and mirroring of infant behavior along with sensitivity and responsiveness to her infant's signals can be created by maternal competencies. Infant's regulatory capacities and interest in feeding can be reinforced by involving the infant in feeding through positive, warm affect, social initiations, responsiveness, and low levels of anxiety and negative reactivity [23]. Furthermore, the study by Pridham et al. supports the idea that it is important to increase the discussion between mother and other family members in solving problems during feeding and other infant-care related issues since they are related with maternal feeding competencies. Support of competence in assigning among mothers and family members who contribute to infant caregiving is a substantial area of clinical practice to be established for health care, early intervention, and home visiting settings, along with interventions targeted directly at feeding competencies [23].

Meanwhile, confidence during feeding refers to the mother's feelings of efficacy in her ability to feed her toddler appropriately, to read and respond to the toddler's signals during feeding, and to display a sense of warmth toward the toddler. In sum, both knowledge and confidence act together to predict performance [24]. Positive parenting behaviors such as responsive feeding practices and breastfeeding duration are related to high parenting self-efficacy. Increasing a parent's level of confidence in performing their role as a caregiver can positively influence a child's growth and development [25].

\section{Dictionary definitions of feeding and self-efficacy}

Self-efficacy is a person's belief that they can be successful when carrying out a particular task. Perceived self-efficacy refers to people's beliefs about 
their capabilities to exercise control over their own activities [26]. Formally, it is the power to produce a desired result or effect [27]. Meanwhile, the definition of feeding is "the act or process of eating or being fed [28]."

\section{The definition of the term based on scientific perspectives}

High self-efficacy individuals believe in their abilities and have positive thoughts surrounding their work. They also have greater prosocial orientation [29]. Therefore, they may be predisposed to view positively any social support they receive. In contrast, low selfefficacy individuals perceive that their abilities are lacking and may feel threatened or may feel additional pressure by the attention and support they receive. It could make them even more self-conscious of their own perceived inadequacies [30]. Several definitions for selfefficacy can be found in dictionaries and throughout the literature related to various disciplines. The meaning of the concept is directly dependent on the discipline and the context in which it is used. The following definitions are used to describe self-efficacy by some disciplines:

Breastfeeding self-efficacy is the primiparous mother's belief and confidence in her ability to exclusively breastfeed her child for the first 6 months after delivery [31]. This was measured using a fivepoint Likert scale, and "strongly agree" or "agree" responses to the correct statements, and "strongly disagree" or "disagree" responses to the negative statements were computed together to classify the study participants as having high breastfeeding selfefficacy. Meanwhile, the converse responses were computed to classify them as having low breastfeeding self-efficacy [31]. Breastfeeding self-efficacy has been used in many breastfeeding studies specifically related to breastfeeding behaviors among mothers.

One of the most important factors in determining breastfeeding duration is the perception of self-efficacy. Perception of self-efficacy is the feeling of the mother of sufficiency related to breastfeeding. Practices projected to increase breastfeeding self-efficacy are highly significant and it is known that those practices encouraging breastfeeding increase the self-efficacy level [32]. Meanwhile, in a study of cooking self-efficacy among university students, Murray et al. defined culinary efficacy as the reported feelings of autonomy and control over being able to cook for themselves [33]. Issues such as the absence of culinary knowledge and skill, financial instability, limited access to healthy food options, and other time/lifestyle restraints may limit their ability to prepare and consume healthy food. Study findings suggest the significance of designing programs with effective approaches to motivate and encourage college students to improve their food behaviors and practices. Another concept is general self-efficacy. This concept is still a broad one that does not focus on one particular behavior. General self-efficacy is associated with active frequent employment of planning, coping, and engaging proactively with goal-directed behaviors [27].

\section{General health behaviors}

Self-efficacy concept has been implemented in numerous general studies of health behaviors. One study by Dominick et al. examined the influence of health literacy on changes in physical activity selfefficacy among Latinas. They defined physical activity self-efficacy or physical activity confidence as one's ability to exercise in various situations (e.g., feeling fatigued, encountering inclement weather, and when on vacation) [34]. Meanwhile, contraceptive self-efficacy refers to the conviction that one can control sexual behavior and engage in contraceptive protection. It refers to motivational barriers or enhancers to contraceptive use among sexually and potentially sexually active individuals [35].

\section{General medicine}

Self-efficacy has been related to better chronic disease self-care among individuals dealing with asthma, diabetes, and arthritis [36]. There are numerous studies that reviewed self-efficacy and its relationship with body treatment, including diet and physical activity behaviors [37], [38]. The study by Martin et al. determined that self-efficacy was related to treatment adherence and participating enthusiastically in physical activity [17]. Hypertension self-efficacy is strongly associated with adherence to five of six prescribed self-care activities among African Americans with hypertension. Ensuring patients feel confident that hypertension is a manageable condition and that they are knowledgeable about appropriate self-care behaviors that are important factors in improving hypertension selfcare and blood pressure control. Health practitioners should assess individuals' self-care activities and direct them toward practical techniques to help boost their confidence in managing their blood pressure [39].

\section{Determine the defining attributes}

Self-efficacy, a component of social cognitive theory, is defined as an individual's judgment regarding his/her abilities to perform certain behaviors [40]. The premise of self-efficacy is that beliefs regarding personal accomplishment or mastery and desired outcomes influence whether a person engages in a behavior, what they will try to attain, and the degree of effort they will exert in a particular behavior. Self-efficacy describes the critical role a person's estimation of his/ her capabilities plays in behavior change, and perceived self-efficacy, which is specific to certain activities, is a major determinant of performance independent of actual underlying skill [29]. Four sources of self-efficacy include active attainment (actual task performance), 
vicarious experience (witnessing others perform the task), verbal persuasion (informing someone they can perform the task), and physiological feedback (physical cues to assess one's progress after engaging in health behaviors) [40].

Self-efficacy appears to play a major role in explaining many health behaviors, and it may demonstrate a fundamental concept in planning nutrition interventions. Researches linking self-efficacy to nutrition and food-related dietary outcomes are needed. Applied to nutrition, self-efficacy may predict which dietary behaviors people feel capable of changing, how much effort they will expend while trying to adopt the new behaviors and how long they will persevere in the face of difficulties.

Furthermore, according to Bandura's selfefficacy theory, the combined effects of parents' knowledge about a task and their confidence in their ability to perform that task successfully influence behavior [40]. Accordingly, maternal confidence has been identified as a significant factor in parent-toddler connections [41] and was found to be associated with competence during feeding [42]. Competence during feeding refers to the mother's feelings of efficacy in her ability to feed her toddler correctly, to read and respond to the toddler's signals during feeding, and to display a sense of warmth toward the toddler. Overall, both knowledge and confidence act together to predict performance [24].

The World Health Organization (WHO) defines complementary feeding as "the process starting when breast milk alone or infant formula alone is no longer sufficient to meet the nutritional requirements of infants, and therefore, other foods and liquids are needed, along with breast milk or a breast-milk substitute" [43]. The WHO stated that "complementary feeding should be timely, meaning that all infants should start receiving foods in addition to breast milk from 6 months onward. It should be adequate, meaning that the complementary foods should be given in amounts, frequency, consistency and using a variety of foods to cover the nutritional needs of the growing child while maintaining breastfeeding [5]. Interventions that provide knowledge and reinforcement can help parents present a wellbalanced, nutritious, and developmentally appropriate diet for toddlers.

The study by Stewart et al. described that there are three aspects of complementary feeding, which contribute significantly to children growth and development [44]. The first category is poor quality foods, which can negatively influence infant and young child growth. The inadequate practice is the second category that includes infrequent feeding, excessively diluted foods with low energy density, inadequate feeding during illness, providing insufficient quantities of food, and non-responsive feeding [45]. The third category, food and water safety, correlates primarily to the infection pathway to stunted growth, but may also contribute through inorganic contaminants and environmental pollutants [46].

The defining attributes of complementary feeding self-efficacy were identified as able to provide nutritious meals appropriately in terms of giving food regularly, with adequate nutrients, that is safe and with appropriate nutrient density while reading and responding to any signals during feeding and displaying a sense of warmth toward the child.

\section{Identify a model case}

A model case is an example of the use of a concept that demonstrates all the defining attributes [2]. The following model cases, in which all of the defining attributes are present, demonstrate the concept of complementary feeding self-efficacy.

Mrs. $B$ is a mother who is the main care-provider for her baby girl aged 9 months and has just completed exclusive breastfeeding for 6 months. Every month she goes to a local health-care facility to check her baby's health and receives health education, including nutrition education, specifically about complementary feeding. She follows all instructions on preparing and giving complementary feeding from the nutritionist and practices it hygienically when preparing and feeding her child. She believes that she could give her child the best complementary feeding. She always cooks the food properly and gives the meals at the right time based on the daily schedule of her baby's mealtime. She feeds her toddler 3 times for meals and 1-2 times for snacks and always makes sure that the food is at the recommended amount for a 6-month-old baby. She makes sure the food contains a variety of food and appropriate amounts. She is attentive to any signal from her baby when she hungry or is already full. She always gives attention and responds to the toddler's signals during feeding as well as displays a sense of warmth when responding to her baby while feeding.

Based on the assumption that Mrs. B feels a sense of efficacy in her ability to feed her toddler appropriately, to read and respond to the toddler's signals during feeding, and to display a sense of warmth toward the toddler. This reflects the mother's self-estimation of competence in her parental role, or as a mother's perception of her ability to positively influence the behavior and development of her children. Mrs. B has made sure that she gives timely, appropriate, adequate nutrition that constitutes safe and appropriate nutrient-dense complementary feeding for her child.

\section{Identify additional cases such as a borderline, related, and contrary cases}

Examining other cases is another important aspect of this process. Examining cases that are not exactly the same as the concept of interest but are 
similar to it or contrary to it in some ways will help make better judgments about which defining attributes or characteristics have the best "fit" [2].

\section{Borderline cases}

Borderline cases are those examples or instances that contain most of the defining attributes of the concept being examined, but not all of them [2]. The following borderline case, which presents only some of the critical attributes, demonstrates what might not be the concept of complementary feeding self-efficacy.

Mrs. $B$ is a mother who is the main care-provider for her baby girl aged 9 months and has just completed exclusive breastfeeding for 9 months. Every month she goes to a local health-care facility to check her baby's health and receives health education, including nutrition education, specifically about complementary feeding. She follows all instructions on preparing and giving complementary feeding from the nutritionist and practicing it hygienically when preparing and feeding her child. She believes that she could give her child the best complementary feeding. She always cooks the food and gives it at the right time based on the daily schedule of her baby's mealtime. She feeds her toddler 2 times for meals and 1 time for snacks and always makes sure that the food is at the recommended amount for a 9-month-old baby. She uses local food that is easily got around the neighborhood without considering the variety of food and does not pay attention to adequate serving amounts. She tries to be aware of any signals from her baby when she is hungry or is already full. She always gives attention and responds to her child's signals during feeding, as well as displays a sense of warmth and responsiveness toward her baby while feeding.

As illustrated in the borderline case above, some, but not all of the defining attributes of compliance were demonstrated. Parents who are borderline often express a willingness to meet some of the nutritional guidelines, while maintaining some control over their decision.

\section{Related cases}

Related cases are instances of the concept that are related to the concept being studied but that do not contain all the defining attributes [2]. The following case was related to the concept of adherence but did not contain all the defining attributes.

Mrs. $B$ is a mother who is the main care-provider for her baby girl aged 9 months and has just completed exclusive breastfeeding for 9 months. Every month she goes to a local health-care facility to check her baby's health and receives health education, including nutrition education, specifically about complementary feeding. She follows all instructions on preparing and giving complementary feeding from the nutritionist and practices it hygienically when preparing and feeding her child when she has time at the weekend. Since she is a working mother, Mrs. B frequently buys commercial complementary food at a store near her house in the morning. She believes that she could give her child the best complementary feeding. She feeds her baby whenever she has finished with her tasks at the kitchen and other housekeeping activities. She feeds her toddler 3 times for meals and 1-2 times for snacks and always makes sure that the food is at the recommended amount for a 9-month-old baby. She makes sure the food contains a variety of food in the appropriate amount. She is attentive to any signal from her baby when she is hungry or is already full but always responds late. She does not always give attention and respond to the toddler's signals during feeding and only sometimes displays a sense of warmth and is responsive toward her baby while feeding.

The related case above demonstrates another mother's practice of complementary feeding. She does all the criteria however she misses some important aspects of good complementary feeding procedures. This case lacks each one of the critical attributes of the concept of complementary feeding self-efficacy.

\section{Contrary cases}

The contrary cases are clear examples of "not the concept [2]." In this contrary case, none of the defining attributes of complementary feeding selfefficacy are demonstrated.

Mrs. B is a mother who tries to care for her baby girl aged 9 months and stopped breastfeeding her baby when the baby was 5 months. She rarely goes to a local health care facility to check her baby's health and get some health education, such as nutrition education, specifically complementary feeding. She is too lazy to cook food by herself for her baby. She believes that she could give her child the best complementary feeding without considering the guideline. She feeds her baby only if she has time to do that. She feeds her toddler 3 times for meals and rarely gives snacks for her baby. She does not pay attention to the variety of food and an appropriate amount of her baby's food. She is not aware of any signals from her baby when hungry or already full. She rarely gives attention and responds to the toddler's signals during feeding nor displays a sense of warmth and responsiveness toward her baby while feeding.

In this contrary case illustrated above, a clear lack of the defining attributes of complementary feeding, self-efficacy is demonstrated by this mother. She is not willing to comply with complementary feeding guidelines and recommendations.

\section{Identify antecedents and consequences}

Antecedents are those events or incidents that must occur before the occurrence of the concept, while 
consequences are those events or incidents that occur as a result of the occurrence of the concept [2].

The importance of the influence of positive attitudes and particularly social approval to mothers' intentions to introduce solids at 6 months is emphasized in some studies. The study by Hamilton et al. showed that older mothers with self-reported normal weight status and strong intentions at 3 months were more likely to conform to guidelines to introduce solids at 6 months of age. Solid introduction at 6 months is performed by mothers when they received information about the benefits as well as having social pressure regarding it [47].

Complementary feeding practice strongly correlates with the education of mother, type of family, profession of father, whether mother is a housewife or job holder [48]. Meanwhile, educational level, occupation of mother, parity, having antenatal care (ANC) follow-up, and birth preparedness were found to be an independent predictor of timely initiation of complementary feeding [49]. Failures in complementary feeding practices such as infrequent feeding may be caused by caregiver time constraints. For example, diluted feeds may be fed due to fears of infant choking and inadequate feeding during illness may be caused by a loss of appetite and food refusals by the infant [44].

On the other hand, lack of income and education impose additional constraints on the healthy toddler parent feeding relationship [50]. Children in lowincome families have a higher incidence of inadequate dietary intake [51] and are at higher risk than others for poor parental feeding behaviors, such as bribery, rigid control, and struggles overeating. For this reason, improving the eating behaviors of poor children under the age of five should be considered a national priority [24].

Meanwhile, non-responsive feeding patterns may arise from misinterpretations of infant cues. Modifiable household factors include access to electricity for refrigeration, poor access to cooking fuel for proper re-heating of meals, or difficulty in accessing sufficient quantities of safe water for proper hygiene practices. Dietary diversity may be restricted by access and affordability of higher quality foods. Dependence on other family members and often times older children within the home, in households where both the mother and father work outside of the home, may limit caregivers' abilities to carry out their infant feeding intentions [44].

Some studies describe the consequences of attributes of complementary feeding self-efficacy (Table 1). When the mother or caregiver applied complementary feeding guidelines including giving a variety of healthy foods, doing hygiene practice, and encouraging children to eat, then there were changes in eating behavior, food intake improvement, and physical growth [45], [52]. Child's nutritional intake can be increased by improving caregiver's attitude; furthermore, improved intake would increase anthropometric growth [53].

\section{Define empirical referents}

Determining the empirical referents for the defining attributes is the final step in concept analysis, which classifies or categorizes the actual phenomena by the existence or presence of the concept itself [2]. From the literature review, it is known that feeding selfefficacy research provides little evidence to support the various methods recommended to identify and/or predict mothers self-efficacy when practicing complementary feeding [11].

Bandura stated that self-efficacy is domainspecific and that measures of generalized self-efficacy are less analytically valuable when observing its role in behavior and behavior change, since an individual's self-efficacy varies across activities and functions [40]. Maternal self-efficacy has long been considered a key determinant of breastfeeding success in low- and highincome countries [54]. Even though some empirical studies have documented the significance of selfefficacy as a driver of behavior change in nutrition interventions in low- and middle-income countries, this kind of work has been lacking for complementary feeding [55].

One study by Zongrone et al. developed maternal self-efficacy complementary feeding questions and a scale based on the self-efficacy theory and the specific CF behaviors prioritized in the intervention. They designed questions that fit with principles of appropriate scale development and subjected to cognitive testing [11].

Meanwhile, Birch et al. developed a childfeeding questionnaire focused on two broad types of

Table 1: Empirical references of the concept of complementary feeding self-efficacy

\begin{tabular}{|c|c|c|c|}
\hline Authors & Year & Empirical reference & Measurement scale \\
\hline Zongrone et al. & 2018 & $\begin{array}{l}\text { Cooking food } \\
\text { Avoiding feeding store } \\
\text { Being able to decide type of food } \\
\text { Raising a healthy child }\end{array}$ & $\begin{array}{l}\text { Maternal self- } \\
\text { efficacy on } \\
\text { complementary } \\
\text { feeding specifically } \\
\text { green leafy } \\
\text { vegetables and egg }\end{array}$ \\
\hline Pridham et al., & 2010 & $\begin{array}{l}\text { Providing of a positive presence in } \\
\text { both affect and behavior, sensitive } \\
\text { responsiveness, and involvement with } \\
\text { the infant, regulation and inhibition of } \\
\text { negative affect, and emotional and } \\
\text { cognitive scaffolding of the infant's } \\
\text { feeding and feeding interaction }\end{array}$ & $\begin{array}{l}\text { Maternal feeding } \\
\text { competencies }\end{array}$ \\
\hline $\begin{array}{l}\text { Crncec, Barnett } \\
\text { and Matthey }\end{array}$ & 2008 & $\begin{array}{l}\text { Confidence in parenting, social supports } \\
\text { being available and infant development }\end{array}$ & $\begin{array}{l}\text { Karitane parenting } \\
\text { confidence scale }\end{array}$ \\
\hline Birch et al. & 2001 & $\begin{array}{l}\text { Perceived feeding responsibility } \\
\text { Perceived parent weight } \\
\text { Perceived child weight } \\
\text { Concern about child weight } \\
\text { Restriction } \\
\text { Pressure to eat } \\
\text { Monitoring }\end{array}$ & $\begin{array}{l}\text { Child feeding } \\
\text { questionnaire } \\
\text { (Parental beliefs, } \\
\text { attitudes, and } \\
\text { practices regarding } \\
\text { child feeding) }\end{array}$ \\
\hline $\begin{array}{l}\text { Teti and } \\
\text { Gelfand et al. }\end{array}$ & 1991 & Handling, feeding, and motivating baby & $\begin{array}{l}\text { Maternal self- } \\
\text { efficacy scale }\end{array}$ \\
\hline $\begin{array}{l}\text { Froman and } \\
\text { Owen }\end{array}$ & 1989 & $\begin{array}{l}\text { Infant care self-efficacy in term of health, } \\
\text { diet, safety behavior }\end{array}$ & $\begin{array}{l}\text { Infant Care Survey } \\
\text { (ICS) }\end{array}$ \\
\hline
\end{tabular}


factors including parental perceptions and concerns regarding their child's risk proneness and parental use of child feeding practices, particularly restriction and pressure to eat, that can hamper the development of adequate self-control of eating in the child [56]. The study by Surkan et al. used parenting self-efficacy to measure mothers' perceived beliefs regarding their performance in performing particular caregiving tasks with their baby [25].

\section{Discussion}

This concept analysis aimed to provide a clear and comprehensive definition of complementary feeding self-efficacy. The complementary feeding practices around the globe are similar and include the fact that few children receive nutritionally adequate and safe complementary foods. In Ethiopia, only $4.2 \%$ of breastfed children of 6-23 months of age have a minimum acceptable diet [57]. A study in India revealed that non-optimal feeding practices include inappropriateness in complementary feeding practices in terms of age at initiation, type of food given as well as amount and frequency [58]. Young children aged less than 2 years in Nepal are at risk for not meeting the WHO recommended infant feeding standards given that only about one in three children are provided with the recommended dietary diversity and acceptable diet [59]. Examining Indonesia's dietary diversity, consumption of iron-rich foods, active feeding and hygienic feeding practices were considered non-optimal [60].

Although the literature review was exhaustive, the production of knowledge is scarce on the concept of complementary feeding self-efficacy. Many of the quantitative studies aimed more exclusively to measuring not to feeding self-efficacy. Self-efficacy measurement scales focusing on very young child care and feeding include small number of feeding aspects. The studies use scales that measure only some aspects of feeding self-efficacy since research has not focused on complementary feeding practices. One study by Zongrone et al. that developed maternal self-efficacy complementary feeding included four questions on feeding family-cooked foods, avoiding feeding storebought snacks, being able to decide the types of foods to feed to the child, and raising a healthy child [11]. The authors developed the complementary feeding self-efficacy concept, but it has not been defined so far except as a broad concept that does not include detailed aspects of complementary feeding. The development of better measures of complementary feeding selfefficacy could be achieved with a clear understanding of its concept.

Meanwhile, Pridham et al. used the parentchild early relational assessment to observe and assess qualities of affect and behavior that the parent and children 1-8 months bring to the interaction [23]. Crncec et al. developed the Karitane parenting confidence feeding competencies to measure perceived parental self-efficacy in terms of confidence in parenting, social supports availability, and infant development in the parents of infants aged 0-12 months [61]. Furthermore, Teti and Gelfand and Froman and Owen developed maternal self-efficacy and infant care self-efficacy scales that measured broad items of caring for children, but they were not specifically focused on feeding selfefficacy [62].

The sources included and reviewed identified four general components of this concept, which include giving adequate food in terms of time, portion, frequency, and variety; providing safe and hygiene food; and creating comfortable and warm environment while children are eating and having appropriate response toward any child cues while eating include hunger and satiety. The first component is to give adequate food in terms of time, portion, frequency, and variety. The WHO stated that complementary feeding should be given at the appropriate time at 6 months while continuing being breastfed. Complementary feeding should be adequate in terms of amount, frequency, consistency, and using a variety of food to fulfill nutrients need for infant growth and development [63].

The second component is to give safe and hygienic food. Food should be prepared with safe procedures to minimize the risk of contamination from pathogenic bacteria. Safe food means it is stored and prepared hygienically, served with clean hands and using clean utensils [64]. The WHO stated there are five keys to safer food, including safe water and ingredients; keeping your hands, utensils, and surfaces clean; cooking food thoroughly; keeping food at safe temperatures; and separating raw from cooked food [65].

The third aspect is to create a comfortable and warm environment while children are eating. The time needed to finish a meal for a child reduces while their age increases for solid and semisolid food [66]. The ability to use a spoon, glasses, or other solid foods increases along with age and practice frequency [66]. The amount of food eaten by children depends on mothers' or caregivers' encouragement while eating [67]. Understanding and appropriate responses from caregivers to hunger cues are important to achieve optimal food intake [66]. It is essential to give food separately for children so that their intake can be measured [68].

The last aspect is to give appropriate responses toward any child cues while eating, including hunger and satiety. Maternal responsiveness to child feeding cues reflects higher levels of general responsiveness during feeding. The study by Hodges et al. revealed that the ability to attend and appropriately respond to children's feeding cues may be facilitated by general sensitivity and responsiveness of the caregiver to the 
child [69]. Hunger cues in infants age 5-12 months include reaches for food, pointing to food, expressing desire for specific food with words or sounds, and getting excited when food is presented [70]. Meanwhile, satiety cues include hands bottle or cup to caregiver, shakes head to say "no more," sputters with tongue and lips, clenches mouth shut, pushes food away, rate of feeding slows down, shakes head to say "no more," plays with utensils, throws utensils, keeps mouth tightly closed, changes posture, and uses hands more actively [70].

Finally, some limitations exist in this analysis. First, only some of the researchers reviewed the articles, which can be considered as selection and information bias. Second, the abstraction and elaboration of the attributes and the definition of the concept could be less accurate due to misinterpretation in many of the articles on feeding self-efficacy. Third, exclusion of articles in languages different from English can contribute to selection bias, because this does not permit understanding a phenomenon of universal nature in its full cultural spectrum. Future research should make comparisons between the existing concepts of feeding self-efficacy based on different age groups since each of them has specific characteristics.

\section{Conclusion}

The results of the importance of complementary feeding self-efficacy in the parenting role are important for health-care professionals. Health professionals can assist mothers in identifying which knowledge and skills should be the primary focus. By knowing mothers complementary feeding self-efficacy, nutrition educators can recognize the forces that drive or inhibit their clients from implementing complementary feeding guidelines. Complementary feeding self-efficacy may predict which practice that mothers feel capable of changing, how much effort they will expend while trying to adopt the new behavior, and how long they will persist in the face of obstacles. The authors recommend that complementary feeding self-efficacy assessment could be used as a screening tool for young age mother, especially new mothers, for their readiness to give complementary feeding to their children. Since the concept of complementary feeding self-efficacy has been defined operationally, it can provide variables for the purposes of research as well.

\section{References}

1. Merriam-Webster's Online Dictionary Concept. Available from: https://www.merriam-webster.com/dictionary/concept. [Last accessed on 2019 Jul 04].
2. Walker LO, Avant KC. Strategies for Theory Construction in Nursing. $4^{\text {th }}$ ed. New Jersey: Pearson Education, Inc.; 2011.

3. Shi L, Zhang J, Wang Y, Caulfield LE, Guyer B. Effectiveness of an educational intervention on complementary feeding practices and growth in rural China: A cluster randomised controlled trial. Public Health Nutr. 2010;13(4):556-65. https://doi.org/10.1017/ s1368980009991364

PMid:19706219

4. Wang J, Chang S, Zhao L, Yu W, Zhang J, Man Q, et al. Effectiveness of community-based complementary food supplement (Yingyangbao) distribution in children aged 6-23 months in poor areas in China. PLoS One. 2017;12(3):e0174302. https://doi.org/10.1371/journal. pone. 0174302

PMid:28319154

5. World Health Organization. Complementary Feeding. Geneva: World Health Organization; 2016. Available from: http://www. who.int/nutrition/topics/complementary_feeding/en. [Last accessed on 2019 Jul 28].

6. Rao S, Swathi P, Unnikrishnan B, Hegde A. Study of complementary feeding practices among mothers of children aged six months to two years a study from coastal south India. Australas Med J. 2011;4(5):252-7. https://doi.org/10.4066/ amj.2011.607

PMid:23393516

7. Smith TM, Dunton GF, Pinard CA, Yaroch AL. Factors influencing food preparation behaviours: findings from focus groups with Mexican-American mothers in Southern California. Public Health Nutr. 2016;19(5):841-50. https://doi.org/10.1017/ s1368980015001949

PMid:26272414

8. Shloim N, Edelson LR, Martin N, Hetherington MM. Parenting styles, feeding styles, feeding practices, and weight status in 4-12 year-old children: A systematic review of the literature. Front Psychol. 2015;6:1849. https://doi.org/10.3389/ fpsyg.2015.01849

PMid:26696920

9. Ruel MT, Alderman H, Maternal and Child Nutrition Study Group. Nutrition-sensitive interventions and programmes: How can they help to accelerate progress in improving maternal and child nutrition? Lancet. 2013;382(9891):536-51. https://doi. org/10.1016/s0140-6736(13)60843-0

PMid:23746780

10. Simmons D, Chapman GE. The significance of home cooking within families. Br Food J. 2012;114:1184-95. https://doi. org/10.1108/00070701211252110

11. Zongrone AA, Menon P, Pelto GH, Habicht JP, Rasmussen KM Constas MA, et al. The pathways from a behavior change communication intervention to infant and young child feeding in Bangladesh are mediated and potentiated by maternal selfefficacy. J Nutr. 2018;148(2):259-66. https://doi.org/10.1093/jn/ $\mathrm{nxx} 048$

PMid:29490102

12. Dewey KG, Adu-Afarwuah S. Systematic review of the efficacy and effectiveness of complementary feeding interventions in developing countries. Matern Child Nutr. 2008;4(Suppl 1):2485. https://doi.org/10.1111/j.1740-8709.2007.00124.x PMid: 18289157

13. Dewey KG. Reducing stunting by improving maternal, infant and young child nutrition in regions such as South Asia: Evidence, challenges and opportunities. Matern Child Nutr. 2016;12(Suppl 1):27-38. https://doi.org/10.1111/mcn.12282 PMid:27187908

14. Ogedegbe G, Mancuso CA, Allegrante JP, Charlson ME. Development and evaluation of a medication adherence selfefficacy scale in hypertensive African-American patients. 
J Clin Epidemiol. 2003;56(6):520-9. https://doi.org/10.1037/ t72395-000

PMid:12873646

15. Coleman PK, Karraker KH. Self-efficacy and parenting quality: Findings and future applications. Dev Rev. 1998;18(1):47-85. https://doi.org/10.1006/drev.1997.0448

16. Kolopaking R, Bardosono S, Fahmida U. Maternal self-efficacy in the home food environment: A qualitative study among lowincome mothers of nutritionally at-risk children in an urban area of Jakarta, Indonesia. J Nutr Educ Behav. 2011;43(3):180-8. https://doi.org/10.1016/j.jneb.2009.10.010

PMid:21094093

17. Martin MY, Person SD, Kratt $P$, Prayor-Patterson H, Kim $Y$, Salas $\mathrm{M}$, et al. Relationship of health behavior theories with self-efficacy among insufficiently active hypertensive AfricanAmerican women. Patient Educ Couns. 2008;72(1):137-45. https://doi.org/10.1016/j.pec.2008.02.012

PMid:18395395

18. Hays NP, Bathalon GP, McCrory MA, Roubenoff R, Lipman R, Roberts SB. Eating behavior correlates of adult weight gain and obesity in healthy women aged $55-65 \mathrm{y}$. Am J Clin Nutr. 2002;75(3):476-83. https://doi.org/10.1093/ajcn/75.3.476 PMid:11864852

19. Vander Wal JS, Johnston KA, Dhurandhar NV. Psychometric properties of the state and trait food cravings questionnaires among overweight and obese persons. Eat Behav. 2007;8(2):21123. https://doi.org/10.1016/j.eatbeh.2006.06.002

PMid:17336791

20. Clark MM, King TK. Eating self-efficacy and weight cycling: A prospective clinical study. Eat Behav. 2000;1(1):47-52. https:/l doi.org/10.1016/s1471-0153(00)00009-x PMid:15001066

21. Luszczynska A, Tryburcy M, Schwarzer R. Improving fruit and vegetable consumption: A self-efficacy intervention compared with a combined self-efficacy and planning intervention. Health Educ Res. 2007;22(5):630-8. https://doi.org/10.1093/her/cyl133 PMid: 17060349

22. Salarkia N, Omidvar N, Zaeri F, Zeinab HE, Neyestani TR. Mother's self-efficacy mediates the relationship between household food insecurity and maternal infant feeding styles. Matern Child Health J. 2016;20(3):602-12. https://doi.org/10.1007/s10995-015-1859-y PMid:26541592

23. Pridham K, Melby JN, Brown R, Clark R. The contribution of infant, maternal, and family conditions to maternal feeding competencies. Parent Sci Pract. 2010;10(1):18-42. https://doi. org/10.1080/15295190903014596

PMid:22140356

24. Horodynski MA, Stommel M. Nutrition education aimed at toddlers: An intervention study. Pediatr Nurs. 2005;31(5):364, 367-72.

PMid:16295151

25. Surkan PJ, Kawachi I, Ryan LM, Berkman LF, Carvalho Vieira LM, Peterson KE. Maternal depressive symptoms, parenting self-efficacy, and child growth. Am J Public Health. 2008;98(1):125-32. https://doi.org/10.2105/ajph.2006.108332 PMid: 18048782

26. Cambridge Online Dictionary. "Self Efficacy". Available from: https://www.dictionary.cambridge.org/dictionary/english/selfefficacy. [Last accessed on 2019 Jul 04].

27. Luszczynska A, Scholz U, Schwarzer R. The general selfefficacy scale: Multicultural validation studies. J Psychol. 2005;139(5):439-57. https://doi.org/10.3200/jrlp.139.5.439-457 PMid:16285214

28. Merriam Webster Dictionary Feeding. Available from: https:// www.merriam-webster.com/dictionary/feeding. [Last accessed on 2019 Feb 25; Last cited on 2019 Jul 04].

29. Bandura A. Health promotion by social cognitive means. Health Educ Behav. 2004;31(2):143-64. https://doi. org/10.1177/1090198104263660

PMid: 15090118

30. Stetz TA, Melba C, Stetz MC, Bliese PD. The importance of self efficacy in the moderating effects of social support on stressorstrain relationships. Work Stress. 2006;20(1):49-59. https://doi. org/10.1080/02678370600624039

31. Minas AG, Ganga-Limando M. Social-cognitive predictors of exclusive breastfeeding among primiparous mothers in Addis Ababa, Ethiopia. PLoS One. 2016;11(10):e0164128. https://doi. org/10.1371/journal.pone.0164128 PMid:27723797

32. Gökçeoğlu E, Küçükoğlu S. The relationship between insufficient milk perception and breastfeeding self-efficacy among Turkish mothers. Glob Health Promot. 2017;24(4):53-61. https://doi. org/10.1177/1757975916635080

PMid:27353118

33. Murray DW, Mahadevan M, Gatto K, O'Connor K, Fissinger A Bailey D, et al. Culinary efficacy: An exploratory study of skills, confidence, and healthy cooking competencies among university students. Perspect Public Health. 2016;136(3):14351. https://doi.org/10.1177/1757913915600195 PMid:26337066

34. Dominick GM, Dunsiger SI, Pekmezi DW, Marcus BH. Health literacy predicts change in physical activity self-efficacy among sedentary Latinas. J Immigr Minor Health. 2013;15:533-9. https://doi.org/10.1007/s10903-012-9666-7

PMid:22733230

35. Longmore MA, Manning WD, Giordano PC, Rudolph JL. Contraceptive self-efficacy: Does it influence adolescents contraceptive use? J Health Soc Behav. 2003;44(1):45-60. https://doi.org/10.2307/1519815

PMid: 12751310

36. Bodenheimer $\mathrm{T}$, Lorig $\mathrm{K}$, Holman $\mathrm{H}$, Grumbach $\mathrm{K}$. Patient self-management of chronic disease in primary care. JAMA. 2002;288(19):2469-75. https://doi.org/10.1001/ jama.288.19.2469

PMid:12435261

37. Leventhal H, Weinman J, Leventhal EA, Phillips LA. Health psychology: The search for pathways between behavior and health. Annu Rev Psychol. 2008;59:477-505. https://doi. org/10.1146/annurev.psych.59.103006.093643 PMid:17937604

38. Pawlak R, Colby S. Benefits, barriers, self-efficacy and knowledge regarding healthy foods; perception of African Americans living in Eastern North Carolina. Nutr Res Pract. 2009;3(1):56-63. https://doi.org/10.4162/nrp.2009.3.1.56 PMid:20016703

39. Warren-Findlow J, Seymour RB, Brunner Huber LR. The association between self-efficacy and hypertension self-care activities among African American adults. J Community Health. 2012;37(1):15-24. https://doi.org/10.1007/s10900-011-9410-6 PMid:21547409

40. Bandura, A. Self-efficacy: The Exercise of Control. New York: W.H. Freeman and Company; 1997.

41. BorW, Sanders MR. Correlates of self-reported coercive parenting of preschool-aged children at high risk for the development of conduct problems. Aust N Z J Psychiatry. 2004;38(9):738-45. https://doi.org/10.1080/j.1440-1614.2004.01452.x PMid:15324339

42. Carruth BR, Ziegler PJ, Gordon A, Barr SI. Prevalence of picky eaters among infants and toddlers and their caregivers' decisions 
about offering a new food. J Am Diet Assoc. 2004;104(1 Suppl1):s57-64. https://doi.org/10.1016/j.jada.2003.10.024 PMid:14702019

43. World Health Organization. Indicators for Assessing Infant and Young Child Feeding Practices. Part I: Definition; 2008. Available from: https://www.who.int/maternal_child_adolescent/ documents/9789241596664/en. [Last accessed on 2019 Jul 04].

44. Stewart CP, lannotti L, Dewey KG, Michaelsen KF, Onyango AW. Contextualising complementary feeding in a broader framework for stunting prevention. Matern Child Nutr. 2013;9(Suppl 2):27-45. https://doi.org/10.1111/mcn.12088 PMid:24074316

45. Aboud FE, Akhter S. A cluster-randomized evaluation of a responsive stimulation and feeding intervention in bangladesh. Pediatrics. 2011;127(5):e1191-7. https://doi.org/10.1542/ peds.2010-2160

PMid:21502222

46. Weisstaub G, Uauy R. Non-breast milk feeding in developing countries: Challenge from microbial and chemical contaminants. Ann Nutr Metab. 2012;60(3):215-9. https://doi. org/10.1159/000338203

\section{PMid:22699772}

47. Hamilton K, Daniels L, White KM, Murray N, Walsh A. Predicting mothers' decisions to introduce complementary feeding at 6 months. An investigation using an extended theory of planned behaviour. Appetite. 2011;56(3):674-81. https://doi. org/10.1016/j.appet.2011.02.002

\section{PMid:21316413}

48. Chapagain RH. Factors affecting complementary feeding practices of Nepali mothers for 6 months to 24 months children. J Nepal Health Res Counc. 2013;11(24):205-7. https://doi. org/10.31729/jnma.1923

PMid:24362612

49. Shumey A, Demissie M, Berhane Y. Timely initiation of complementary feeding and associated factors among children aged 6 to 12 months in Northern Ethiopia: An institution-based cross-sectional study. BMC Public Health. 2013;13:1050. https://doi.org/10.1186/1471-2458-13-1050

PMid:24195592

50. Duncan GJ, Brooks-Gunn J. Family poverty, welfare reform, and child development. Child Dev. 2000;71(1):188-96. https:// doi.org/10.1111/1467-8624.00133

PMid:10836573

51. Knol LL, Haughton B, Fitzhugh EC. Food insufficiency is not related to the overall variety of foods consumed by young children in low-income families. J Am Diet Assoc. 2004;104(4):640-4. https://doi.org/10.1016/j.jada.2004.01.018

PMid:15054350

52. Bhandari N, Mazumder S, Bahl R, Martines J, Black RE, Bhan MK, et al. An educational intervention to promote appropriate complementary feeding practices and physical growth in infants and young children in rural Haryana, India. J Nutr. 2004;134(9):2342-8. https://doi.org/10.1093/jn/134.9.2342 PMid: 15333726

53. Bhandari N, Bahl R, Nayyar B, Khokhar P, Rohde JE, Bhan MK. Food supplementation with encouragement to feed it to infants from 4 to 12 months of age has a small impact on weight gain. J Nutr. 2001;131(7):1946-51. https://doi.org/10.1093/ jn/131.7.1946

PMid:11435512

54. Tuthill EL, McGrath JM, Graber M, Cusson RM, Young SL. Breastfeeding self-efficacy: A critical review of available instruments. J Hum Lact. 2016;32(1):35-45. https://doi. org/10.1177/0890334415599533

PMid:26319113
55. Thomas JS, Yu EA, Tirmizi N, Owais A, Das SK, Rahman S, et al. Maternal knowledge, attitudes and self-efficacy in relation to intention to exclusively breastfeed among pregnant women in rural Bangladesh. Matern Child Health J. 2015;19(1):49-57. https://doi.org/10.1007/s10995-014-1494-z

PMid:24752315

56. Birch LL, Fisher JO, Grimm-Thomas K, Markey CN, Sawyer R, Johnson SL. Confirmatory factor analysis of the child feeding questionnaire: A measure of parental attitudes, beliefs and practices about child feeding and obesity proneness. Appetite. 2001;36(3):201-10. https://doi.org/10.1006/appe.2001.0398 PMid:11358344

57. Abeshu MA, Lelisa A, Geleta B. Complementary feeding: Review of recommendations, feeding practices, and adequacy of homemade complementary food preparations in developing countries lessons from Ethiopia. Front Nutr. 2016;3:41. https:// doi.org/10.3389/fnut.2016.00041

\section{PMid:27800479}

58. Ashwini S, Katti SM, Mallapur MD. Comparison of complementary feeding practices among urban and rural mothers a cross sectional study Al Ameen. J Med Sci. 2014;7(4):257-64. https:// doi.org/10.4103/2230-8598.127172

59. Khanal V, Sauer K, Zhao Y. Determinants of complementary feeding practices among Nepalese children aged 6-23 months: Findings from demographic and health survey 2011. BMC Pediatr. 2013;13:131. https://doi.org/10.1186/1471-2431-13-131 PMid:23981670

60. Blaney S, Februhartanty J, Sukotjo S. Feeding practices among Indonesian children above six months of age: A literature review on their magnitude and quality (part 1). Asia Pac J Clin Nutr. 2015;24(1):16-27. https://doi.org/10.1002/nur.20271 PMid:25740738

61. Crncec R, Barnett B, Matthey S. Development of an instrument to assess perceived self-efficacy in the parents of infants. Res Nurs Health. 2008;31(5):442-53. https://doi. org/10.1891/1061-3749.18.3.210

PMid:18297638

62. Crncec R, Barnett B, Matthey S. Review of scales of parenting confidence. J Nurs Meas. 2010;18(3):210-40.

PMid:21290926

63. WHO Programme of Nutrition. Complementary Feeding of Young Children in Developing Countries: A Review of Current Scientific Knowledge; 1998. Available from: https://www.apps.who.int/iris/ handle/10665/65932. [Last accessed on 2019 Jul 04].

64. Pan American Health Organization World Health Organization. Guiding Principles for Complementary Feeding of the Breastfed Child; 2002. Available from: https://www.who.int/nutrition/ publications/guiding_principles_compfeeding_breastfedpdf. [Last accessed on 2019 Jul 04].

65. World Health Organization. Infant and Young Child Feeding Model Chapter for Textbooks for Medical Students and Allied Health Professionals. Geneva: World Health Organization; 2009.

66. Engle PL, Bentley M, Pelto G. The role of care in nutrition programmes: Current research and a research agenda. Proc Nutr Soc. 2000;59(1):25-35. https://doi.org/10.1017/ s0029665100000045

PMid: 10828171

67. Gittelsohn J, Shankar AV, West KP Jr., Faruque F, Gnywali T, Pradhan EK. Child feeding and care behaviors are associated with xerophthalmia in rural Nepalese households. Soc Sci Med. 1998;47(4):477-86. https:// doi.org/10.1016/s0277-9536(98)00131-2

PMid:9680231

68. Shankar AV, Gittelsohn J, West KP Jr., Stallings R, Gnywali T, Faruque $F$. Eating from a shared plate affects food consumption in 
Vitamin A-deficient Nepali children. J Nutr. 1998;128(7):1127-33. https://doi.org/10.1093/jn/128.7.1127

\section{PMid:9649595}

69. Hodges EA, Johnson SL, Hughes SO, Hopkinson JM, Butte NF, Fisher JO. Development of the responsiveness to child feeding cues scale. Appetite. 2013;65:210-9. https://doi.org/10.1016/j. appet.2013.02.010

PMid:23419965

70. Mahan LK, Raymond JL. Krause's Food and the Nutrition Care Process. New York: Prentice Hall; 2017. 